\title{
Erratum to: Oocyte cryopreservation: is it time to remove its experimental label?
}

\author{
Nicole Noyes • Jeffrey Boldt • Zsolt Peter Nagy
}

Published online: 31 March 2010

(C) Springer Science+Business Media, LLC 2010

Erratum to: J Assist Reprod Genet

Volume 27 Issue 2-3 (February/March 2010)

page 73

DOI 10.1007/s10815-009-9382-y

The original version of this article unfortunately contained a mistake.

Reference number 19 should be:

Kuleshova L, Gianaroli L, Magli C, Ferraretti A, Trounson A. Birth following vitrification of a small number of human oocytes: case report. Hum Reprod. 1999;14:3077-9.

The paper was published in 1999, so 2002 on the published article should be replaced with 1999.

The online version of the original article can be found at http://dx.doi. org/10.1007/s10815-009-9382-y.

\footnotetext{
N. Noyes $(\triangle)$

NYU Fertility Center, NYU School of Medicine,

660 First Avenue, Fifth Floor,

New York, NY 10016, USA

e-mail: nnoyes01@gmail.com

J. Boldt

Assisted Fertility Services, Community Health Network, Inc.,

Indianapolis, IN 46256, USA

Z. P. Nagy

Reproductive Biology Associates,

1150 Lake Hearn Drive,

Atlanta, GA 30342, USA
} 